\title{
Gut barrier function in malnourished patients
}

\author{
F K S Welsh, S M Farmery, K MacLennan, M B Sheridan, G R Barclay, P J Guillou, \\ J V Reynolds
}

\begin{abstract}
Background-The integrity of the gastrointestinal mucosa is a key element in preventing systemic absorption of enteric toxins and bacteria. In the critically ill, breakdown of gut barrier function may fuel sepsis. Malnourished patients have an increased risk of postoperative sepsis; however, the effects of malnutrition on intestinal barrier function in man are unknown.
\end{abstract}

Aims-To quantify intestinal barrier function, endotoxin exposure, and the acute phase cytokine response in malnourished patients.

Patients-Malnourished and well nourished hospitalised patients.

Methods-Gastrointestinal permeability was measured in malnourished patients and well nourished controls using the lactulose:mannitol test. Endoscopic biopsy specimens were stained and morphological and immunohistochemical features graded. The polymerase chain reaction was used to determine mucosal cytokine expression. The immunoglobulin G antibody response to endotoxin and serum interleukin 6 were measured by enzyme linked immunosorbent assay.

Results-There was a significant increase in intestinal permeability in the malnourished patients in association with phenotypic and molecular evidence of activation of lamina propria mononuclear cells and enterocytes, and a heightened acute phase response.

Conclusions-Intestinal barrier function is significantly compromised in malnourished patients, but the clinical significance is unclear.

(Gut 1998;42:396-401)

Keywords: protein-energy malnutrition; intestinal permeability; endotoxin; cytokine

Protein malnutrition is prevalent in hospitalised patients. ${ }^{12}$ The enhanced susceptibility of malnourished patients to infection and postoperative sepsis has long been recognised ${ }^{34}$ and attributed predominantly to impaired systemic immune function. ${ }^{56}$ The importance of gastrointestinal defences, in particular mucosal immune function and barrier activity against endogenous microbes and toxins, is increasingly being recognised as integral to the modern view of sepsis and organ failure. ${ }^{78}$ Evidence from experimental models and clinical kwashiorkor suggests that malnutrition alters mucosal immune defences and compromises the gut's barrier function against invasion by microorganisms or their products. ${ }^{9}$ In animal models, malnutrition is associated with villous atrophy and loss of intestinal weight, protein and RNA content, ${ }^{10}$ macromolecule transepithelial absorption, ${ }^{11}$ abnormal mucin, ${ }^{12}$ reduced secretory immunoglobulin A (s-IgA), ${ }^{13}$ and impaired efficacy of oral vaccines. ${ }^{14}$ Increased transport of macromolecules has been observed in biopsy specimens from malnourished children, ${ }^{15}$ as well as reduced s-IgA levels and affinity ${ }^{12}$ and reduced efficacy of oral vaccines. ${ }^{16}$

There is little information on gastrointestinal defences in malnourished patients in the developed world. Reynolds $e t a l^{17}$ reported increased levels of systemic immunoglobulin G (IgG) antibodies to the food proteins $\beta$-lactoglobulin and gliadin in malnourished patients, indirectly suggesting altered mucosal immunity. The aim of this study was to determine whether gut barrier function was impaired in malnourished patients and to investigate whether altered barrier function was associated with changes in intestinal immune function and morphology. In the light of the current model of sepsis, an attempt was made to determine whether increased intestinal permeability was associated with evidence of endotoxin exposure or a heightened acute phase response.

\section{Materials and methods}

PATIENTS

Ethical approval was obtained from the ethics committee of St James's University Hospital, according to the Helsinki agreement. Fifty three patients were studied. Each patient was categorised as being well nourished (control), mild/moderately malnourished, or severely malnourished according to two parameters. The first, subjective global assessment (SGA), ${ }^{18}$ is based on history and examination by two independent clinicians without knowledge of anthropometric or biochemical data. The second parameter was defined as a score of 98.5 or less on the nutritional risk index (NRI), calculated according to the following formula: $(1.519 \times$ plasma albumin $(\mathrm{g} / \mathrm{l}))+(0.417 \times$ (current weight/usual weight) $\times 100 .{ }^{19}$ This was further categorised as mild/moderate $(83.5<\mathrm{NRI}$ score $<98.5)$ or severe $(\mathrm{NRI}<83.5)$. Postoperative patients, patients with evidence of infection or sepsis, patients receiving total parenteral nutrition, patients taking steroids or non-steroidal inflammatory drugs, and patients with peptic ulcer disease, inflammatory bowel disease, or jaundice were excluded from the study.

INTESTINAL PERMEABILITY

Intestinal permeability was quantified using the lactulose:mannitol (L:M) test. ${ }^{20}$ The prin- 
ciple of this test is that lactulose and mannitol are absorbed from the small intestine by different pathways. Mannitol, the smaller molecule, is absorbed via the transcellular pathway and lactulose by the paracellular route. Both probes are rapidly excreted in the urine. In conditions associated with increased permeability, the $\mathrm{L}: \mathrm{M}$ excretion ratio is increased through relatively greater absorbance of lactulose. After a six hour fast, the patients provided a pretest urine specimen, emptied the bladder, and then drank a test solution containing $5 \mathrm{~g}$ lactulose, 2 $\mathrm{g}$ mannitol, and $22.4 \mathrm{~g}$ glucose in $100 \mathrm{ml}$ water. All urine passed during the subsequent five hours was collected into $0.2 \mathrm{~g}$ chlorhexidine (as preservative). Glucose was included in the test solution as an osmotic "filler", to render the solution hyperosmolar, which increases disaccharide absorption in such disaccharide/ monosaccharide sugar tests. ${ }^{21}$ The use of an osmotic filler has been previously shown to increase the discrimination of sugar tests in distinguishing normal patients from patients with coeliac disease. ${ }^{22}$

Urinary lactulose was measured by paper chromatography ${ }^{23}$ using a Chromoscan recording and integrating scanning densitometer (Joyce-Loebl \& Co Ltd, Gateshead, UK). The coefficient of variance of this assay was $\pm 2 \%$. Urinary mannitol was measured by a modified spectrophotometric method following its oxidation with periodate, and the coefficient of variance for this assay was $\pm 2.5 \%$. Results are expressed as a ratio of the percentage dose excreted of the two molecules, and the normal range for the urinary L:M ratio is $0-0.028 .^{20}$

\section{INTESTINAL MORPHOLOGY/}

IMMUNOHISTOCHEMISTRY

Patients underwent endoscopy, and three biopsy samples were taken from the second part of the duodenum, distal to the ampulla of Vater. One biopsy sample was fixed in $10 \%$ buffered formalin, embedded in paraffin, and 5 $\mu \mathrm{m}$ sections were cut and stained with haematoxylin and eosin. Intestinal villous height and crypt depth were measured using the microscope eyepiece graticule. At least ten villi or crypts were measured for each section and the mean value determined. A second biopsy specimen was snap frozen in liquid nitrogen, and $5 \mu \mathrm{m}$ sections were cut in a cryostat and stained using a standard three stage immunoperoxidase method as follows. After blocking of non-specific binding sites with 5\% serum in phosphate buffered saline (PBS) and avidin and biotin blocking solutions (Vector $\mathrm{AB}$ Blocking Kit, Vector, UK), tissue sections were incubated at room temperature for thirty minutes with a primary antibody (table 1 ) or serum

Table 1 Primary antibodies used

\begin{tabular}{lllll}
\hline Antibody & Cellular distribution & Source & Description & Dilution \\
\hline CD3 & T cells & Dako & Rabbit polyclonal & 1 in 100 \\
CD30 & Late activated T cells & Dako & Mouse monoclonal IgG1 & 1 in 40 \\
CD68 & Macrophages & Dako & Mouse monoclonal IgG1 & 1 in 50 \\
HLA-DR & $\begin{array}{c}\text { B cells, activated T cells, } \\
\text { macrophages }\end{array}$ & Dako & Mouse monoclonal IgG1 & 1 in 100 \\
IgA & Secretory IgA & Dako & Rabbit polyclonal & 1 in 500 \\
\hline
\end{tabular}

Source: Dako, High Wycombe, Bucks, UK. (negative control). After being washed in PBS, sections were incubated with a biotinylated second layer antibody (swine anti-rabbit polyclonal primary antibodies or rabbit anti-mouse monoclonal primary antibodies) for thirty minutes at room temperature. After further washing, samples were incubated with StrepABComplex/HRP (DAKO) and visualised with a diaminobenzidine chromogen (Sigma, Poole, Dorset, UK). Sections were counterstained with haematoxylin. The numbers of positive cells and the intensity of staining within cells were scored from +1 to +4 by a consultant pathologist (K $\mathrm{M})$ who was unaware of the source of the tissue.

INTESTINAL MUCOSAL HLA-DR, TUMOUR NECROSIS FACTOR $\alpha$ (TNF- $\alpha$ ), AND INTERLEUKIN 10 (IL-10) GENE EXPRESSION: RNA EXTRACTION AND REVERSE TRANSCRIPTASE POLYMERASE CHAIN REACTION (PCR)

All general and laboratory reagents used were of AnalaR or equivalent grade and were purchased from Sigma or BDH (Poole, Dorset, UK) unless stated otherwise. The third endoscopic duodenal biopsy sample obtained was immediately snap frozen in liquid nitrogen. RNA was isolated using a cationic surfactant method (Catrimox; VH Bio Ltd, Newcastle upon Tyne, UK), ${ }^{24}$ washed with $2 \mathrm{M}$ lithium chloride and $75 \%$ ethanol, dried and resuspended in molecular biology grade water containing $1 \mathrm{mM}$ dithiothreitol and $2.5 \% \mathrm{RNasin}$ (Promega, Southampton, Hants, UK). Isolated RNA was reversed transcribed into complementary DNA (cDNA) using Moloney murine leukaemia virus reverse transcriptase (Promega), $0.5 \mu \mathrm{g}$ random hexamer primers (Promega) and $1 \mathrm{mM}$ dNTPs, in a final reaction volume of $20 \mu \mathrm{l}$, in the prescence of $2.5 \% \mathrm{RNasin}$ and $3 \mathrm{mM} \mathrm{MgCl}$. The reaction mixture was incubated at $42^{\circ} \mathrm{C}$ for one hour, followed by five minutes at $95^{\circ} \mathrm{C}$ to inactivate the enzyme. cDNA was stored at $4{ }^{\circ} \mathrm{C}$ until used.

PCR was performed in a semiquantitative fashion, by co-amplifying a housekeeping gene, ${ }^{25}$ glyceraldehyde-3-phosphate dehydrogenase (G3PDH), in each PCR, and expressing the amount of cDNA of the gene of interest as a ratio to G3PDH. G3PDH is commonly used as an internal standard because its cellular expression remains unchanged under most conditions. The optimum ratio of G3PDH primer to HLA-DR/TNF- $\alpha / \mathrm{IL}-10$ primer, PCR cycle number, and annealing temperature were determined in preliminary PCR titration experiments. Aliquots $(1 \mu \mathrm{l})$ of cDNA template were subjected to PCR amplification, using primers specific for HLA-DR, TNF- $\alpha$, and IL-10 (table 2). The $20 \mu \mathrm{l}$ reaction mixture contained $1 \times$ PCR Thermo buffer (Promega), with $2 \mathrm{mM} \mathrm{MgCl}_{2}$, sense and antisense primers, $0.2 \mathrm{mM} \mathrm{dNTPs}$ and 1 unit Thermus aquaticus (Taq) DNA polymerase (Promega). After a "hot start" at $95^{\circ} \mathrm{C}$, thermocycling was performed for 35-40 cycles, consisting of denaturing at $95{ }^{\circ} \mathrm{C}$ for 60 seconds, primer annealing at $51-55{ }^{\circ} \mathrm{C}$ for 60 seconds, and primer extension at $72{ }^{\circ} \mathrm{C}$ for 60 seconds, on a 
Table 2 PCR primer sequences

\begin{tabular}{lll}
\hline Gene & Primer sequence 5' - 3" & $\begin{array}{l}\text { PCR product size } \\
\text { (base pairs) }\end{array}$ \\
\hline HLA-DR & $\begin{array}{l}\text { TCA TCC AGG CCG AGT TCT ATCTGT CTC TGA } \\
\text { CAC TCC TGT GGT }\end{array}$ & 312 \\
TNF- $\alpha$ & $\begin{array}{l}\text { CAG AGG GAA GAG TTC CCC AGCCT TGG TCT GGT } \\
\text { IL-10 }\end{array}$ & $\begin{array}{l}\text { AGG AGA CG } \\
\text { AGT CGC CAC CCT GAT GTC TCCCT GGG GGA GAA }\end{array}$ \\
G3PDH & $\begin{array}{l}\text { CCT GAA G } \\
\text { GAG TCA ACG GAT TTG GTC GTTTC CCG TTC TCA }\end{array}$ & 223 \\
& GCC TTG AC & 177
\end{tabular}

$\overline{\text { TNF, tumour necrosis factor; IL-10, interleukin 10; G3PDH, glyceraldehyde-3-phosphate dehy- }}$ drogenase.

Biometra Personal Thermo-cycler (Biometra Ltd, Maidstone, Kent, UK). PCR product was electrophoresed on a $2 \%$ agarose gel (ICN Biochemicals Inc, OH, USA), visualised by ethidium bromide fluorescence, and quantified by computerised image analysis (Gelbase/ Gelblot software (version 2.1); UVP Products, Cambridge, UK). All PCR experiments were performed in triplicate, and the mean ratio for each patient calculated to ensure reproducibility of results.

SERUM ASSAYS

Evidence of chronic exposure to endotoxin was sought by measuring the IgG antibody response to endotoxin. Serum concentrations of anti-endotoxin-core antibody (EndoCAb) of the IgG class were quantified using an enzyme linked immunoabsorbent assay (ELISA), as previously described. ${ }^{26}$ Serum interleukin 6 (IL-6) was measured using a commercially available ELISA (R\&D Systems, Abingdon, Oxfordshire, UK) and serum C-reactive protein (CRP) determined by routine autoanalysis (Beckman autoanalyser).

\section{STATISTICAL ANALYSIS}

Data are expressed as medians with interquartile range in parentheses. Statistical analysis was performed using Statview software (Apple computers Inc, Abacus Concepts Inc, Berkeley, CA, USA). Non-parametric analysis was performed using the Kruskal-Wallis and Mann-Whitney U tests. Correlation was determined using linear regression analysis. A value of $\mathrm{p}<0.05$ was considered significant.

\section{Results}

PATIENT DEMOGRAPHICS

Table 3 shows the characteristics of the control and malnourished patients. The groups were matched for age, sex, and the presence of neoplastic disease. By SGA, 22 patients were con-

Table 3 Patient demographics

\begin{tabular}{llll}
\hline & Controls & $\begin{array}{l}\text { Mild/moderate } \\
\text { malnutrition }\end{array}$ & Severe malnutrition \\
\hline Number of patients & 22 & 20 & 11 \\
Age (y) & $68(60-79)$ & $71(60-77)$ & $70(61-73)$ \\
M:F & $15: 7$ & $13: 7$ & $8: 3$ \\
Neoplastic disease (n) & 19 & 14 & 11 \\
Gastro-oesophageal carcinoma (n) & 12 & 12 & 9 \\
Pancreatic carcinoma (n) & 1 & 0 & 0 \\
Colorectal carcinoma (n) & 6 & 1 & 0 \\
Other neoplastic (n) & 0 & 1 & 2 \\
Plasma albumin (g/l) & $39(33-41)$ & $36(33-40)$ & $31(25-34)^{\star \star}$ \\
Nutritional risk index (NRI) & $99(90-102)$ & $90(86-96)$ & $81(70-86)^{\star \star}$ \\
\hline
\end{tabular}

Values are medians, with interquartile range in parentheses.

${ }^{\star \star} \mathrm{p}<0.01$, Kruskal Wallis test.

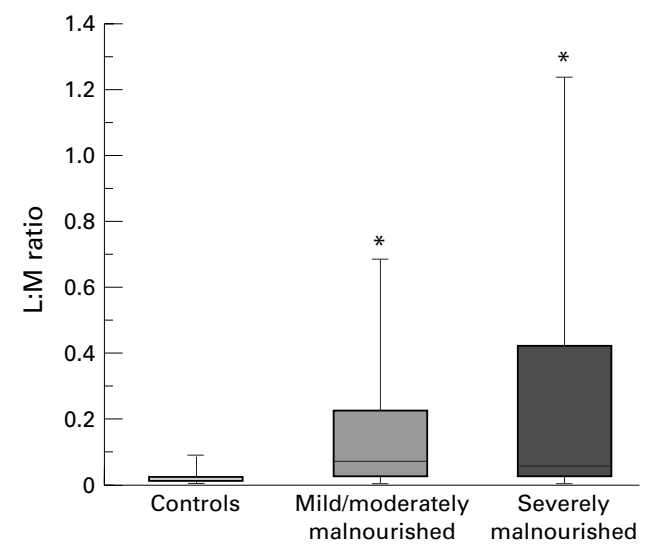

Figure 1 Intestinal permeability in control, mild/moderately malnourished, and severely malnourished patients. Intestinal permeability is represented on the y axis by the urinary lactulose:mannitol ratio (L:M ratio). Bars with horizontal lines represent interquartile range and median values, with the "whiskers" representing the range. There is a significant increase in L:M ratio in the mild/moderate and severely malnourished patients compared with the controls $\left({ }^{\star} p<0.01\right.$, Kruskal-Wallis test).

sidered well nourished, 20 were mild or moderately malnourished, and 11 were severely malnourished. The median plasma albumin level was significantly decreased in the malnourished groups compared with the controls. There was a significant and sequential reduction in median NRI from the control patients (99 (90-102)), through the mild/ moderately malnourished (90 (86-96)), to the severely malnourished patients $(81(70-86))(\mathrm{p}$ $=0.0001$, Kruskal-Wallis) .

INTESTINAL PERMEABILITY

Figure 1 shows the urinary L:M ratios in the three patient groups. The median L:M ratio in the control patients was $0.012(0.004-0.022)$, which is within normal limits. In contrast, there was a significant increase in L:M ratio in both the mild/moderately malnourished patients (0.068 (0.021-0.227)) and the severely malnourished patients $(0.056 \quad(0.018-0.423))$ compared with the controls $(\mathrm{p}=0.009$, Kruskal-Wallis). While there was no significant difference in intestinal permeability between the two malnourished patient groups, linear regression analysis showed a significant $(\mathrm{p}=$ 0.006) inverse correlation between $L: M$ ratio and nutritional status, as defined by NRI.

INTESTINAL MORPHOLOGY

Intestinal histological and immunohistochemical examination was performed in 12 control and 11 malnourished (six mild/moderate, five severe) patients. Histological findings were normal in both groups. There was no evidence of villous atrophy or mucosal disruption in any patient. Villous height was 398 (370-418) $\mu \mathrm{m}$ in the well nourished group compared with 384 (361-439) $\mu \mathrm{m}$ in the malnourished patients ( $\mathrm{p}$ $=0.2)$. Crypt depth was $77(63-68) \mu \mathrm{m}$ in the well nourished group and $100(73-143) \mu \mathrm{m}$ in the malnourished group $(\mathrm{p}=0.07)$.

INTESTINAL IMMUNOHISTOCHEMISTRY

Table 4 gives the mucosal immunohistochemistry scores. There was no significant difference 
Table 4 Immunohistochemistry results

\begin{tabular}{lll}
\hline & $\begin{array}{l}\text { Controls } \\
(n=12)\end{array}$ & $\begin{array}{l}\text { Malnourished } \\
(n=11)\end{array}$ \\
\hline Secretory IgA & $2(2-2)$ & $2(2-2)$ \\
CD3 & $2(1-2)$ & $3(2-3)^{\star \star}$ \\
CD68 & $2(2-2)$ & $3(3-3)^{\star \star}$ \\
CD30 & $2(2-2)$ & $2(2-3)$ \\
HLA-DR (lamina propria & $3(2-3)$ & $3(3-3)^{\star \star}$ \\
$\quad$ mononuclear cells) & & $3(3-3)^{\star \star}$ \\
HLA-DR (epithelial cells) & $0(0-1)$ & 3 \\
\hline
\end{tabular}

Values are medians, with interquartile range in parentheses. ${ }_{\star \star \star} \mathrm{p}<0.01$, Mann-Whitney U test.
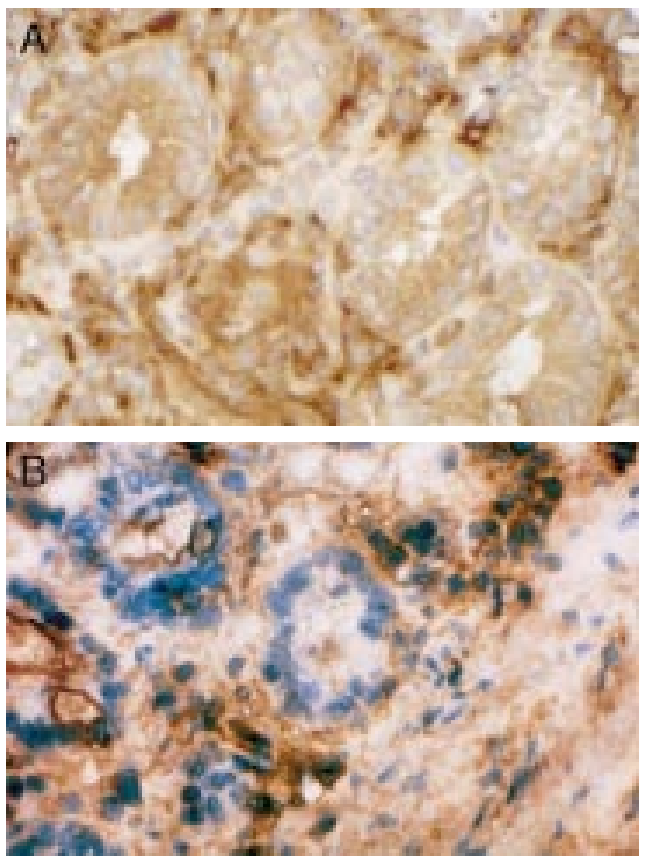

Figure 2 Frozen sections of human duodenal mucosa stained with anti-HLA-DR monoclonal antibody (original magnification $\times 140$ ). A section from a malnourished patient $(A)$ shows intense HLA-DR expression on both lamina propria mononuclear cells and enterocytes. A section from a control patient (B) shows less HLA-DR expression in the lamina propria cells and little detectable HLA-DR expression in enterocytes.

between groups in expression of s-IgA. There was a significant $(p<0.01)$ increase in CD3 positive cells ( $T$ cells) in the mucosa of the malnourished patients. There was also a significant $(p<0.01)$ increase in CD68 positive cells (macrophages) infiltrating the lamina propria in sections from malnourished patients. Expression of the activation marker HLA-DR was significantly $(p<0.01)$ increased on lamina propria mononuclear cells (lymphocytes and macrophages) in the malnourished group. An additional feature was the significant $(\mathrm{p}<0.01)$ upregulation of enterocyte HLA-DR expression on intestinal epithelial cells from malnourished patients (fig 2). There was no significant increase in $\mathrm{T}$ cells expressing the late activation marker, CD30.

MUCOSAL GENE EXPRESSION

Table 5 gives the results of the reverse transcriptase PCR based experiments. This was conducted in 16 controls and 13 (seven mild/moderate, six severe) malnourished patients. In keeping with the immunohistochemical data, there was a significant $(p<0.05)$ increase in mucosal expression of HLA-DR in
Table 5 Mucosal gene expression

\begin{tabular}{lll}
\hline & Controls $(n=16)$ & $\begin{array}{l}\text { Malnourished } \\
(n=13)\end{array}$ \\
\hline HLA-DR : G3PDH & $0.81(0.62-0.95)$ & $1.01(0.85-1.07)^{\star}$ \\
TNF- $\alpha$ : G3PDH & $0.12(\mathrm{ND}-0.38)$ & $0.15(\mathrm{ND}-0.63)$ \\
IL-10 : G3PDH & $0.68(0.58-1.05)$ & $0.39(\mathrm{ND}-0.73)^{\star}$ \\
\hline Values are median PCR product ratio (interquartile range). \\
${ }^{\star} \mathrm{p}<0.05$, Mann-Whitney U test. \\
ND, not detectable; TNF, tumour necrosis factor; IL-10, inter- \\
leukin 10; G3PDH, glyceraldehyde-3-phosphate dehydroge- \\
nase.
\end{tabular}

the malnourished patients. There was a significant reduction in mucosal IL-10 expression in the malnourished patients ( $\mathrm{p}<0.05 v$ controls). There was no difference between groups in expression of the TNF- $\alpha$ gene.

ANTI-ENDOTOXIN LEVELS AND THE ACUTE PHASE RESPONSE

The median IgG EndoCAb in the well nourished patients was 101 (59-158) MU/ml. No significant increase in IgG EndoCAb was evident in either the mild/moderately malnourished (155 (78-295) MU/ml) or the severely malnourished patients (158 (59-242) MU/ml) ( $\mathrm{p}=0.29 v$ controls, Kruskal-Wallis).

There was a significant and sequential increase $(p<0.0001)$ in IL-6, from the controls $(3(<3-7) \mathrm{pg} / \mathrm{ml})$, through the mild/moderately malnourished $(6(4-13) \mathrm{pg} / \mathrm{ml})$ to the severely malnourished patients (27 (23-40) $\mathrm{pg} / \mathrm{ml})$. Similarly, a significant $(\mathrm{p}<0.05)$ increase in CRP was evident in severely malnourished patients, with median values of $7(6-15) \mathrm{g} / \mathrm{l}$ in the controls, $6(5-33) \mathrm{g} / \mathrm{l}$ in the mild/ moderately malnourished, and 28 (16-54) g/l in the severely malnourished patients. There was a significant inverse correlation $(\mathrm{p}=$ $0.0006, r=0.47$, linear regression) between IL-6 and nutritional status, determined by NRI. Furthermore, there was a significant positive correlation $(\mathrm{p}=0.002, r=0.45$, linear regression) between IL-6 and L:M ratio.

\section{Discussion}

The aim of this study was to determine whether the consistent experimental data that identify impaired gut barrier function in malnutrition could be corroborated in malnourished humans. Malnutrition is an independent risk factor for infection and sepsis, especially after operative trauma. ${ }^{3}{ }^{19}$ The study hypothesis was that altered gut barrier function and mucosal immunology would be important in the malnourished patient, and therefore a comprehensive investigation of mucosal immunology, gut barrier function, and analysis of the sequelae of altered barrier function was performed. The study showed an increase in intestinal permeability in malnourished patients in association with phenotypic and molecular evidence of activation of lamina propria mononuclear cells and enterocytes, and a heightened acute phase response. The study thus confirmed experimental observations, but may have added significance in that the changes demonstrated occurred in a relevant group of hospital patients rather than at the extremes of malnutrition induced experimentally or observed in kwashiorkor. 
The increase in intestinal permeability inversely correlated with the NRI score, an index of the severity of malnutrition and a validated parameter of operative risk. ${ }^{19}$ In the present study, the increased L:M ratio was due to a relative increase in the amount of lactulose absorbed through the paracellular pathway, representing absorption through the tight junctions or cell extrusion zones and areas of damaged mucosa. In animal models, protein malnutrition in rats resulted in increased intestinal transport of bovine serum albumin. ${ }^{11}$ Moreover, bacterial translocation and mortality from sepsis was enhanced in malnourished animals challenged with proinflammatory stimuli, ${ }^{27}{ }^{28}$ and bacterial adherence to mucosal epithelial cells was increased. ${ }^{29}$ In malnourished children, Heyman et al ${ }^{15}$ showed increased transport of the horseradish peroxidase antigen in jejunal biopsy specimens. In the only directly comparable clinical studies, the data are inconsistent: Maxton et $a l^{30}$ studied five malnourished patients who were receiving long term enteral nutrition and showed that four of five patients had increased urinary lactulose:rhamnose ratios. However, Elia et $a l^{11}$ could not confirm this observation in patients following total starvation or very low energy diets. It is not known if increased intestinal permeability correlates with an increased potential for bacterial translocation in humans. The difference between malnourished and well nourished patients in our investigation is clear, however, and, if comparable with other conditions associated with increased intestinal permeability, ${ }^{32} 33$ may be associated with an increased risk of the systemic inflammatory response syndrome and sepsis.

The mechanism underlying increased permeability did not appear to be related to altered morphology, since there was no evidence of villous shortening or mucosal atrophy, although potential ultrastructural changes were not studied. While malnutrition in experimental animals and in kwashiorkor may produce villous atrophy, this study and others suggest that gross villous architecture is preserved in malnourished hospital patients. ${ }^{17} 34$

Impaired gut barrier function was closely associated with abnormal gastrointestinal mucosal immunology. The mechanism appeared to be related to a relative imbalance of proinflammatory and cellular immune mechanisms over anti-inflammatory and humoral mechanisms. In this study, the increased number of $\mathrm{T}$ cells and macrophages in the mucosa is consistent with local immunoinflammation, and furthermore the enhanced expression of the major histocompatibility complex (MHC) class II antigen HLA-DR on these cells suggests cellular activation. An intriguing observation was the evidence for enhanced expression of MHC class II antigen on duodenal epithelial cells. The expression of MHC class II on intestinal epithelial cells is site dependent and barely detectable in normal human duodenum. ${ }^{35}$ In vitro studies have shown that enterocytes can present antigen to primed $\mathrm{T}$ cells, suggesting that MHC class II positive enterocytes may present peptides from cellular membrane compartments to cells of the immune system within the lamina propria. ${ }^{36}$ The expression of MHC class II in the gastrointestinal epithelium is increased in many diseases, including Crohn's disease, graft versus host disease, and radiation enteritis, and may be associated with evidence of mucosal $\mathrm{T}$ cell activation. ${ }^{37}$ The function of MHC class II positive enterocytes is unclear in this study, but if they transport, process, and present luminal antigens to lamina propria lymphocytes, they may play an important role in initiating or amplifying the local immunoinflammatory response, leading to tissue damage and promoting gut barrier compromise. The precise trigger for cellular activation is unclear, but it may be the result of direct exposure of cells to bacteria, toxins, or other antigens, although systemic factors cannot be excluded. Moreover, whether the heightened immune activity is the cause or effect of increased intestinal permeability is at present unknown.

The molecular evidence of increased mucosal gene expression of HLA-DR in malnourished patients is consistent with the immunohistochemical findings. Moreover, the finding of a significant decrease in mucosal IL-10 expression in malnourished patients supports the thesis that a relative shift from an anti-inflammatory to pro-inflammatory cytokine profile occurs.

Serum IL-6 and CRP were significantly increased in malnourished patients, directly correlating with the severity of malnutrition. This finding may be related to systemic inflammation, the hypermetabolism of cancer, or be triggered by the consequences of gut barrier failure. The direct correlation between the L:M ratio and serum IL-6 levels supports the latter possibility. It is not clear which gut factors could mediate this, but we found no evidence that endotoxin was involved. The IgG response to IgG EndoCAb is an indirect measure of chronic endotoxin exposure and appears to be a more reliable and reproducible method of assessing endotoxaemia than using the amoebocyte lysate assay. ${ }^{38}$ The lack of difference between the malnourished and control patients may be genuine, although an alternative possibility is that impaired systemic humoral immunity in malnutrition has precluded normal antibody generation. ${ }^{39}$ It may be that the systemic response mirrors the local immunoinflammatory response, perhaps mediated by locally generated cytokines, and that further studies should address this question.

In conclusion, intestinal permeability is increased in malnourished patients in association with a heightened acute phase response. The mechanism appears to be associated with evidence of activation of the mucosal immune system and enterocytes, in conjunction with relative suppression of the anti-inflammatory cytokine IL-10. The clinical significance of these findings, in particular whether they are important in the pathophysiology of the increased risk of sepsis in the malnourished patient, and whether these changes can be reversed by gut directed therapies will require further study. 
The authors would like to acknowledge the excellent technical help given by Jill Rothwell, Gastroenterology Unit, Leeds General Infirmary, and Jane Ramsdale, Department of Pathology, St James's Hospital, Leeds.

$1 \mathrm{McWhirter} J \mathrm{P}$, Pennington CR. Incidence and recognition of malnutrition in hospital. BMF 1994;308:945-8.

2 Bistrian BR, Blackburn G, Vitale J, et al. Prevalence of malBistrian $\mathrm{BR}$, Blackburn $\mathrm{G}$, Vitale J, et al. Prevalence of mal-
nutrition in general medical patients. $\mathscr{f} A M A$ 1976;253 1567-70.

3 Windsor JA, Hill GL. Protein depletion and surgical risk. Aust N Z F Surg 1988;58:711-15.

4 Meguid MM, Debonis D, Meguid V, et al. Complications of abdominal operations for malignant disease. Am f Surg 1988;156:341-5.

5 Chandra RK. Nutrition, immunity and infection: present knowledge and future directions. Lancet 1983;1:688-91.

6 Reynolds JV, Redmond HP, Ueno N, et al. Impairment of macrophage activation by protein malnutrition. Cell Immunol 1992;139:493-504.

7 Deitch EA. Multiple organ failure. Pathophysiology and potential future therapy. Ann Surg 1992;216:117-34.

8 Carrico CJ, Meakins JL, Marshall JC, Fry D, Maier RV. Multiple organ failure syndrome: the gastrointestinal tract: Multiple organ failure syndrome: the gastrointestinal
the motor of MOF? Arch. Surg 1986;121:197-201.

9 Chandra RK, Wadhwa M. Nutritional modulation of intestinal mucosal immunity. Immunol Invest 1989;18:119-26.

10 Steiner M, Bourges HR, Freedman LS, Gray SJ. Effect of starvation on the tissue composition of the small intestine starvation on the tissue composition of
in the rat. Am $\mathcal{F}$ Physiol 1968;215:75-7.

11 Worthington BS, Boatman ES, Kenny GE. Intestinal absorption of intact proteins in normal and proteindeficient rats. Am $\mathcal{F}$ Clin Nutr 1974; 27:276-86.

12 Sherman P, Forsteer J, Roomi N, et al. Mucin depletion in the intestine of malnourished rats. Am F Physiol 1985;248: G418-23.

13 Sullivan DA, Vaerman JP, Soo C. Influence of severe protein malnutrition on rat lacrimal, salivary and gastrointestinal immune expression during development, adulthood and ageing. Immunology 1993;78:308-17.

14 Barry WS, Pierce NF. Protein deprivation causes reversible impairment of mucosal immune response to cholera toxoid/ toxin in rat gut. Nature 1979;281:64-5.

15 Heyman M, Boudraa G, Sarrut S, et al. Macromolecular transport in jejunal mucosa of children with severe malnutransport in jejunal mucosa of children with severe

16 Chandra RK. Nutrition and immunity: lessons from the past and new insights into the future. Am f Clin Nutr 1991; 53:1087-101

17 Reynolds JV, O'Farrelly C, Feighery C, et al. Impaired gut barrier function in protein malnourished patients. $\mathrm{Br} \mathcal{F}$ Surg 1996;83:1288-91.

18 Baker JP, Detsky AS, Weeson DE, et al. Nutritional assessment. A comparison of clinical judgement and objective measures. N Engl f Med 1982;306:969-72.

19 The Veterans Affairs Total Parenteral Nutrition Cooperative Study Group. Perioperative total parenteral nutrition in surgical patients. N Engl f Med 1991;325:525-32.

20 Juby LD, Rothwell J, Axon ATR. Lactulose/mannitol test: an ideal screen for coeliac disease. Gastroenterology 1989;96:79-85.
21 Laker MF, Menzies IS. Increase in human intestinal permebility following ingestion of hypertonic solutions. $\mathcal{F}$ Physiol 1977;265:881-94.

22 Cobden I, Hamilton I, Rothwell J, Axon ATR. Cellobiose/ mannitol test: physiological properties of probe molecules and influence of extraneous factors. Clin Chim Acta 1985;148:53-62.

23 Menzies IS. Quantitative estimation of sugars in blood and urine by paper chromatography using direct densitometry. f Chromatogr 1973;81:109-27.

24 Macfarlane DE, Dahle CE. Isolating RNA from whole blood: the dawn of RNA-based diagnosis? Nature 1993; 362:186-8.

25 Chen D, Klebe RJ. Controls for validation of relative reverse transcription-polymerase chain reaction assays. PCR Methods and Applications 1993;3:127-9.

26 Scott BB, Barclay GR. Endotoxin-polymyxin complexes in an improved enzyme-linked immunosorbant assay for IgG antibodies in blood donor sera to Gram-negative endotoxin core glycolipid. Vox Sang 1987;52:272-80.

27 Deitch EA, Winterton J, Ma L, Berg RD. Gut as a portal of entry for bacteraemia; the role of protein malnutrition. Ann Surg 1987;205:681-92.

28 Deitch EA, Ma JA, Ma L, Berg RD, Specian RD. Protein malnutrition predisposes to inflammatory induced gutorigin septic states. Ann Surg 1990;211:560-8.

29 Chandra RK, Gupta SP. Increased bacterial adherence to respiratory and buccal epithelial cells in protein-energy malnutrition. Immunol Infect Dis 1991;1:55-7.

30 Maxton DG, Menzies IS, Slavin B, Thompson RP. Small intestinal function during enteral feeding and starvation in man. Clin Sci 1989;77:401-6.

31 Elia M, Goren A, Behrens R, et al. Effect of total starvation and very low calorie diets on intestinal permeability in man. Clin Sci 1987;73:205-10.

32 Ziegler TR, Smith RJ, O'Dwyer ST, et al. Increased intestinal permeability associated with infection in burn patients. Arch Surg 1988;123:1313-19.

33 Pape HC, Dwenger A, Regel G, et al. Increased gut permeability after multiple trauma. Br F Surg 1994;81:850-2.

34 Sedman PC, MacFie J, Palmer MD, et al. Preoperative total parenteral nutrition is not associated with mucosal atrophy or bacterial translocation in humans. Br F Surg 1995;82: 1663-7.

35 Mayer L, Eisenhardt D, Salomon P, et al. Expression of Class II molecules on intestinal epithelial cells in humans. Gastroenterology 1991;100:3-12

36 Bland PW, Warren LG. Antigen presentation by epithelial cells of the rat small intestine. 1. Kinetics, antigen 1986;58:1-7.

37 Sanderson IR, Walker WA. Uptake and transport of macromolecules by the intestine: possible role in clinical disorders. (An update). Gastroenterology 1993;104:622-39.

38 Barclay GR. Endogenous endotoxin-core antibody (Endo$\mathrm{CAb}$ ) as a marker of endotoxin exposure and a prognostic indicator: a review. Prog Clin Biol Res 1995;392:263-72.

39 Nohr CW, Tchervenkov JI, Meakins JL, Christou NV. Malnutrition and humoral immunity: short-term acute nutritional deprivation. Surgery 1985;98:769-76. 